\title{
BRAINSTORMING E A APLICAÇÃO DO MODELO CLASSICO
}

\section{ARTIGO ORIGINAL}

GRANADO, Graziane Correa da Silva ${ }^{1}$

GRANADO, Graziane Correa da Silva. Brainstorming e a aplicação do modelo clássico. Revista Científica Multidisciplinar Núcleo do Conhecimento. Ano 05, Ed. 10, Vol. 18, pp. 05-20. Outubro de 2020. ISSN: 2448-0959, Link de acesso: https://www.nucleodoconhecimento.com.br/engenharia-deproducao/brainstorming

\section{RESUMO}

Sob a perspectiva de um mundo globalizado, empresas de diferentes portes e segmentos estão em busca de novos métodos de gestão. Dito isso, o presente artigo tem como objetivo demonstrar a aplicabilidade da metodologia Brainstorming, criada por Osborn, que tem como função criar o máximo de ideias possíveis relacionadas a um determinado assunto durante um período de tempo, soluções de baixo custo, evitando qualquer tipo de decisão precipitada. Assim, sendo um instrumento bastante relevante para as organizações, uma vez que busca propor soluções de forma conjunta, proporcionando uma ampla perspectiva de ideias para resolver um problema, facilitando a escolha da melhor decisão. Essa técnica pode ser aplicada em diversos seguimentos para diversos problemas, sejam de gestão, em projetos, desenvolvimento de novos produtos, entre outros. Existem muitas variações distintas do brainstorming, optamos por utilizar o brainstorming clássico e ilustrar a forma correta de sua aplicação e evidenciar sua grande aplicabilidade no mundo Atual. Para a realização do presente trabalho foi realizado um estudo de caso. Com o estudo de caso e a partir da análise de materiais já publicados se chegou à conclusão de que

1 Pós-Graduação Lato Sensu, em nível de especialização em Gerenciamento de Projetos, Pós-Graduação Lato Sensu, em nível de especialização em Engenharia da Qualidade, Graduação em Engenharia de Produção. 
um brainstorming bem elaborado e ministrado pode lançar soluções inovadoras para a situação problema ou como pode também sugerir soluções simples que farão toda a diferença. Além disso, o estudo de caso trouxe ao conhecimento outro benefício como o envolvimento da equipe no processo, no qual foi possível verificar que o brainstorming contribui elevando a satisfação e a motivação dos colaboradores.

Palavras-chave: Brainstorming, criatividade, inovação, solução, problema.

\section{INTRODUÇÃO}

Brainstorming é uma palavra da língua inglesa que pode ser traduzida como tempestade de ideias para chegar ao melhor resultado, num mundo competitivo onde inovar é preciso. Essa técnica é importante para as organizações visto que ela busca por soluções de forma conjunta possibilitando uma perspectiva ampla de ideias e maneiras de se resolver um problema facilitando a escolha da melhor decisão. Com o brainstorming, é possível aproveitar toda a criatividade e inteligência de colaboradores das mais diferentes áreas para construir um plano de ação amplo e assertivo frente a um problema e esse ponto foi o que motivou a escolha do tema, as vantagens de sua utilização são muitas, desde uma valorização dos funcionários até a resolução da questão abordada.

A inovação é vital para a vantagem competitiva de longo prazo nas empresas, tornouse importante gerenciar este processo, e nas ferramentas utilizadas para gerenciamento de processos de inovação encontramos o brainstorming, é importante ressaltar que essa técnica potencializa o processo criativo. Dessa forma, é preciso contextualizar a criatividade e entender quais são os fatores que estão relacionados a ela, com o intuito de compreender todo o processo de maneira mais clara e ampla.

Existem várias versões distintas do brainstorming, dentre elas destacamos a mais comum, o brainstorming clássico para deixar claro a simplicidade do método e os bons resultados. O uso dessa técnica corresponde a busca por resultados imediatos, que apresentam ausência de regras rígidas a serem seguidas, porém o brainstorming não deve ser realizado como um bate-papo, no qual as ideias simplesmente aparecem, 
ele possui uma metodologia, conta com etapas que precisam ser seguidas para que ele seja o mais eficiente possível. Partindo desse princípio, e de forma a proporcionar uma contribuição teórica ao tema, esse trabalho tem como objetivo propor um passo a passo de fácil compreensão para realização do brainstorming clássico.

Para compreender melhor a utilização dessa técnica na terceira seção apresento um estudo de caso. O problema enfrentado pela empresa se encontrava na distribuição demanda entre os colaboradores a forma como a mesma vinha sendo realizada, de forma irregular o objetivo é encontrar soluções de baixo custo e de aplicação imediata através da técnica de brainstorming.

\section{DESENVOLVIMENTO}

\section{INOVAÇÃO E CRIATIVIDADE}

Em decorrência da globalização, empresas de diferentes portes e segmentos estão buscando novas alternativas de gestão, a fim de gerenciar seus conhecimentos de modo adequado com o propósito de gerar inovação e competitividade, e consequentemente a formação de redes empresariais. (ARAÚJO et. al., 2010).

A inovação começou a ser considerada um fator decisivo para o desenvolvimento e o sucesso das empresas, e até mesmo dos países. O entendimento que envolve esta questão aponta que uma produção eficiente e de qualidade com uma gama maior de produtos não é suficiente para se alcançar um patamar alto e lucrativo, assim, é preciso que sejam ofertadas novidades, aperfeiçoamentos e até mesmo aprimoramentos de produtos já existentes. O âmbito das inovações é representado pelos atos de gerar, desenvolver e implantar ideias ou procedimentos novos. "Estes podem ser novos produtos ou serviços, novas tecnologias para procedimentos produtivos, novas estruturas ou sistemas administrativos, isto é, ter componentes novos no sentido de inovar" (CHIBÁS et. al., 2013 p.16). Neste sentido, a inovação é uma alternativa capaz de promover mudanças significativas na organização, tanto como uma forma de responder às alterações nos ambientes internos ou externos, 
quanto como uma ação antecipada aos concorrentes, para que o ambiente possa ser influenciado. (CHIBÁS et. al., 2013)

O nível de inovação do produto é um fator muito importante. Deste modo, o processo geracional de inovações pode ser conduzido pela utilização de métodos, técnicas e ferramentas capazes de auxiliar esse processo, e ainda pela construção de uma atmosfera que permita o desenvolvimento de novas ideias. Sendo estes recursos essenciais para aumentar a competitividade da organização. (HIDALGO; ALBORS, 2008)

Portanto, esse processo pode ser iniciado pela obtenção de informações proporcionadas pelos usuários, clientes e funcionários, em que estas podem ser aprofundadas através do chamado brainstorming. (HOLT, 1988)

Neste contexto, o brainstorming passa a existir para propor soluções a deficiências identificadas (COOPER, 2008). E ainda, proporcionar grandes ideais que são utilizadas por muitas organizações atualmente (DUGOSH, et. al, 2000).

Quando se trata de brainstorming, é importante destacar que essa técnica é uma das ferramentas que potencializam o processo criativo. Assim, é necessário contextualizar a criatividade e entender quais fatores estão associados a ela, a fim de compreender todo o processo em uma perspectiva mais ampla e clara (PAROLIN, 2001).

Segundo a etimologia das palavras, o termo criatividade provém do latim "creare", que significa criar, inventar, fazer algo novo. Enquanto o termo inovação deriva-se do latim innovare, que tem por significado tornar novo, mudar ou alterar as coisas, introduzindo-as às novidades, renovando-as. (PAROLIN, 2001)

A criatividade é uma das características do ser humano que mais o diferencia de outras espécies existentes. Essa capacidade nos permite raciocinar desde o princípio da humanidade. Se existir um estudo aprofundado sobre o tema, possivelmente seríamos capazes de entender melhor essa capacidade humana, lidando de forma mais positiva com esse aspecto (LUBART, 2007). 
Ao analisar cronologicamente as teorias sobre criatividade, assim como Wechsler sugeriu, verifica-se que, na tradição não-empírica, a criatividade é como uma inspiração divina, como forma de intuição e como loucura (WECHSLER, 1998). No entanto, a abordagem biológica, marcada pela teoria evolucionista de Darwin, caracteriza a criatividade como uma manifestação da força criadora essencial à vida, "sempre gerando novas espécies, com inesgotável variedade de formas peculiares, sem precedentes e sem repetições. Seu componente principal é a hereditariedade, não sendo possível educar uma pessoa para a criatividade." (AMORIM; FREDERICO, 2008, p.2)

Sob a perspectiva psicológica, o behaviorismo centra-se na predição e no controle do comportamento. Ele aponta o processo criativo como um fenômeno consequente de combinações mentais que são armazenadas através das experiências vivenciadas pelas pessoas, considerando a criatividade o resultado de uma associação com algo concreto de sua vida (SENS, 1998).

Na psicanálise, a criatividade é procedente do conflito no inconsciente que provoca um comportamento de criação ou de neurose. (KNELLER, 1978)

De acordo com a psicologia humanista, três representantes - Rogers, Maslow e Rollo May - apontam que a criatividade é movida pela tendência humana que busca à auto realização, sendo assim, é imprescindível um ambiente que permita a liberdade de escolha e o livre-arbítrio para qualquer indivíduo, visando as motivações individuais intrínsecas e extrínsecas do meio em que ele vive. $\mathrm{Na}$ abordagem cognitiva, a criatividade está relacionada com a inteligência e a capacidade de solucionar problemas. Neste contexto, destaca-se a abordagem criada por Howard Gardner (1994), que teve como questionamento a centralidade da inteligência nas competências lógico-matemáticas e linguísticas, resultando na teoria das inteligências múltiplas. Portanto, as abordagens da psicologia humanista e de Gardner (1994) são muito utilizadas pelas organizações, em vista da aplicação das múltiplas inteligências sobre os parâmetros capitalistas, associando a criação dos produtos e a solução de problemas aos resultados financeiros, como a redução de custos e despesas e o aumento da demanda. (ALENCAR e FLEITH, 2003) 
No entanto, diante de muito tempo de investigação ao longo dos anos, Todd Lubart define a criatividade como uma característica que tem a capacidade de realizar uma produção, podendo esta ser, ao mesmo tempo, nova e adaptada ao contexto em que ela se manifesta. Neste sentido, entende-se por uma produção inovadora, aquela que ainda não foi criada ou explorada (LUBART, 2007).

Por outro lado, uma resposta nova não deve ser considerada simplesmente como uma produção criativa. Ela deve ser adaptada, com intuído de satisfazer as dificuldades encontradas em diferentes situações vivenciadas por diferentes pessoas (LUBART, 2007). Decerto, dentre os estudos sobre a criatividade, verifica-se que quando se é interrogado a respeito das suas concepções, tanto os sujeitos como os avaliadores fazem alusão desse duplo aspecto de novidade e adaptação (LUBART, 2007).

Mesmo que haja uma variedade de definições sobre o papel representativo do processo criativo, não há nenhuma regra absoluta para defini-lo. Julgar a criatividade implica uma concordância social, caso haja um grupo que determine o grau de criatividade de alguma obra ou projeto (LUBART, 2007). Assim, ao avaliar deve-se levar em conta a variação desse grau e das concepções sobrepostas aos requisitos, dando como exemplo: o caráter de novidade ou o de adaptação, a qualidade técnica da obra ou o caráter de necessidade da sociedade (LUBART, 2007)

Entende-se então, que quando se trata da criatividade e do processo criativo, muitos conceitos são levantados, nos quais são abordados desde as origens do pensamento criativo até a possível classificação do grau criativo de um projeto. Algo extremamente relevante ao projeto de brainstorming, visto que este configura-se como a prática de uma ideia adaptada que tem o propósito de satisfazer a uma necessidade específica. Como também a inovação pode ser gerada por meio da utilização de métodos, técnicas e ferramentas a fim de construir um ambiente capaz de estimular a criação de novas ideias, também através do chamado brainstorming. (LUBART, 2007)

No entanto, nos limites do presente artigo, há uma distinção entre a criatividade e inovação, em que a primeira condiz com a geração de ideias, enquanto a segunda condiz com a prática e com a realização da implementação supracitada anteriormente. 
Ambos os processos se fundem no conceito de ideias que podem ser promovidas em um brainstorming.

\section{BRAINSTORMING}

A literatura sobre o tópico exibe alguns termos recorrentes, tais como: geração de ideias, ideação e gestão de ideias. Assim sendo, a geração de ideias compõe uma das principais preocupações de organizações que buscam desenvolver inovações de modo sistemático (BARBIERI, 2009)

Em 1957, Osborn desenvolveu formalmente o brainstorming, apresentando como argumento, o aumento da qualidade e quantidade de ideias desenvolvidas pelos membros do grupo (PAULUS; DZINDOLET, 1993). Dando importância a geração de ideias como uma parte crítica do processo de inovação, o brainstorming é considerado por muitas empresas como um instrumento bastante eficaz, em razão da sua capacidade de desenvolver um grande número de ideias criativas (RIETZSCHEL, 2006)

Portanto, ele atua como um estimulante da criatividade por permitir o compartilhamento verbal de ideias sem apresentar críticas no decorrer do processo geracional de ideias (KING; SCHLICKS UPP, 2002). É válido destacar que os grupos desempenham um importante papel nas organizações e compreender os fatores que dificultam ou facilitam esse processo criativo do grupo é de extrema importância. (NIJSTAD; DE ABREU, 2002)

Deste modo, criado em 1939, por Alex Osborn, o método brainstorming é um instrumento associado a criatividade e comumente utilizado no planejamento de projetos, com o intuito de buscar soluções a um determinado problema. Assim, Osborn o define como $o$ ato de usar o cérebro para tumultuar um problema (OSBORN, 1987).

Este método é bastante utilizado com o propósito de gerar um número grande de ideias para um determinado tempo, e, apesar de ser utilizado por muitas pessoas que 
trabalham em setores diretamente ligados a criatividade, a aplicação do brainstorming pode ir além disso. (OSBORN,1987)

No entanto, sabe-se que esse processo é utilizado em grandes corporações, como por exemplo, agências de publicidade e comunicação, e departamentos de jornalismo, uma vez que se é necessário gerar constantemente soluções, com a finalidade de otimizar o processo de resolução dos problemas (OSBORN,1987)

Com o propósito de verificar a aplicabilidade do brainstorming, Osborn realizou pesquisas e testes em um grupo, a fim de avaliar o pensamento coletivo e sua capacidade de produção de ideias. Na época, a maioria dos dados foram obtidos através de estudos realizados nas áreas da educação, da indústria, das vendas e do governo. Em 1955, Osborn fez esses testes em instituições educacionais, como a Universidade de Akron, de Búfalo e de Pitsburgo, contribuindo para o desenvolvimento de um conhecimento mais aprofundado na área. (OSBORN, 1987)

Como resultado desse estudo, foram propostos os seguintes princípios:

A ideação - torna-se mais produtiva quando se exclui a crítica exercida simultaneamente. - Considerou-se este princípio importante, devido à educação e à experiência terem treinado muitos adultos a pensar mais judiciosamente do que criadoramente. Daí resulta a tendência que revela a própria fluência de ideias, por aplicarem demasiadamente cedo a faculdade crítica.

Quanto mais ideias, melhor. - Aqueles que tiveram mais experiência com o -brainstormingll são unânimes, a afirmar que, na ideação, a quantidade contribui para melhorar a qualidade. Caso após caso, as últimas 50 ideias produzidas em uma dessas sessões revelaram média mais alta em qualidade do que as primeiras 50 .

A idealização em grupo pode ser mais produtiva do que a individual - Verificou-se este princípio mediante uma série de experiências na Universidade de Búfalo. Durante as mesmas, metade do grupo deixou a sala. Recomendou-se aos que ficaram para escrever as próprias sugestões sem se consultarem. Durante a segunda parte de cada uma dessas experiências, os outros membros do grupo voltaram, trocando de lugares 
com a primeira metade; depois, em conjunto e oralmente, passaram a idear o mesmo problema. (OSBORN, 1987)

Em suas publicações, Osborn trata sobre a técnica fazendo uso de diversos casos práticos, no qual pode-se destacar quatro princípios fundamentais para um bom desempenho e produtividade de qualquer sessão de Brainstorming (OSBORN, 1962).

A saber:

Banir a crítica: deve-se suspender o julgamento, contrário às ideias, até mais tarde.

Aceitar de bom grado a "polia louca": quanto mais extremada a ideia, melhor, uma vez que é mais fácil diminuir-Ihe a intensidade do que aumentá-la.

Procurar quantidade: Quanto maior o número de ideias, mais fácil será encontrar as convenientes.

São desejáveis combinações e melhoramentos: além de contribuírem com as próprias ideias, os participantes devem sugerir como as ideias de outros podem transformarse em ideias melhores ou como duas ou mais ideias podem juntar-se para formarem outra melhor (OSBORN, 1962).

Incluindo-se a esses quatro princípios, o autor ainda pondera a respeito de orientações como:

Quantidade ideal de participantes: sugere-se cerca de 12 pessoas, sendo que alguns membros mais proativos teriam a função de, logo de início ou na "arrancada", dar ritmo na fluidez de ideias, cuidando para não tomarem conta de toda a sessão. Também orienta para que parte do grupo seja de pessoas envolvidas no projeto, empresa ou contexto para o qual a sessão gerará ideias e outra parte seja de pessoas com pontos de vista diversos.

Membros: o ideal seria a seleção de membros de mesmo nível hierárquico sendo o cenário mais crítico aquele em que chefe e subordinado encontram-se em uma mesma sessão. 
Papel de facilitador: cabe a este convocar ou convidar participantes, apresentar o problema ou questão central, apresentar os princípios de forma descontraída e informal, prezando pelo seu cumprimento, coordenar a sessão visando manter a motivação ou produtividade de ideias altas, evitar que a atenção do grupo se divida em dois ou mais debates paralelos e agradecer pela participação de todos compartilhando as ideias geradas pelo grupo com o mesmo.

Registro das ideias: uma pessoa deve ficar encarregada de registrar a produção do grupo, sem ater-se a detalhes ou almejar registrar $100 \%$ do que é dito, entretanto, como um jornalista ou observador, deve buscar relatar o máximo das ideias produzidas.

Clima: deve ser descontraído, informal. Ainda sugere que sessões produtivas ocorram em volta de lanches e "piqueniques". Para o autor, um clima de sucesso de uma sessão é quando há diversão, rivalidade, cordialidade (OSBORN, 1962).

Osborn (1962) ainda traz diversos comentários acerca da produção criativa em grupo destacados abaixo:

Facilitador - "Insucesso do Brainstorming é geralmente devido a erros de liderança (facilitação)". Ex.: líder assumindo papel preponderante, gera receio nos mais tímidos de "abrir a boca". Ou, o líder deixando surgir manifestações de críticas, o grupo deixa de apresentar melhores resultados.

Produtividade - Um dos casos comentados mostra que o processo criativo em grupo foi $44 \%$ maior que o individual, o que se dá, segundo o autor, devido ao "poder de associação" - uma ideia de uma pessoa inspira e desperta outra ideia em outra pessoa e a rivalidade e competitividade.

"Um perfeccionismo complexo (autocrítica) sufoca o esforço e aborda as ideias". Disso exemplificou que um dos participantes mais "hábeis" (criativos individualmente) ficou murmurando durante uma sessão e não contribuiu por achar que suas ideias e palpites não eram bons o suficiente. 
Cada sessão deve atacar um problema específico e não geral, caso contrário, a sessão vai se arrastar sem foco ou objetivo.

Fatos em demasia sufocam a espontaneidade necessária em trabalhos de grupos.

Os grupos podem variar no "tamanho dos espíritos", ou seja, formar grupo de novatos ou veteranos. Para Osborn (1962), é indiferente o gênero do indivíduo. O importante é que existam alguns membros de iniciativa.

Sugere-se adotar o uso de uma campainha ou algo semelhante para que, após a apresentação dos quatro princípios, seja este o instrumento de aviso em caso da violação de algum princípio por parte dos membros. "À frente do chefe está uma campainha de tipo antigo. $O$ chefe explica que a fará soar sempre que um membro do grupo violar qualquer das regras"

Reforçar positivamente ideias construídas pelo grupo. "O chefe anima especialmente as ideias que resultam de outra anterior. Esta reação em cadeia merece de tal maneira desenvolver-se completamente [...]" (OSBORN, 1962).

\subsection{O BRAINSTORMING CLÁSSICO}

Há diversas versões distintas do brainstorming, como o clássico, o anônimo, o individual, o construtivo-destrutivo, o didático, o eletrônico, o visual etc. No presente estudo, optamos por fazer uso do brainstorming clássico para demonstrar corretamente sua aplicação e evidenciar sua grande aplicabilidade no mundo Atual.

A criatividade está relacionada ao raciocínio, considerada como uma característica exclusiva do ser humano ligada aos sentidos e emoções que estimulam o processo de adquirir e indexar informações.

Conforme Baxter (2000), o brainstorming clássico pode ser dividido em várias fases:

Orientação: é o marco inicial do brainstorming em que o coordenador orienta sua equipe a respeito do problema ou briefing a ser trabalhado. 
Preparação: nesta etapa é estipulado pelo coordenador um tempo considerável, geralmente em torno de 30 minutos, para que os integrantes da equipe possam formular suas ideias. Todas as informações, precisam ser registradas pelo relator.

Análise: após a prática da fase anterior, é realizada uma nova marcação de tempo, em torno de 15 minutos, para que possa haver uma conjunção das ideias propostas segundo algum critério definido pelo grupo.

Ideação: ainda dentro do tempo determinado previamente pelo coordenador, a seguinte fase se inicia, a fase de associação, em que se caracteriza pela seleção das propostas mais relevantes, a fim de serem detalhadas.

Incubação: de acordo com Baxter, é considerado que quando se aplica corretamente a técnica criativa, essa etapa torna-se dispensável. Nesta etapa se incide com a interrupção e retomada da técnica que pode variar de horas a dias, dependendo da satisfação do rendimento da mesma. Durante esse intervalo de tempo, pode-se colher outros dados, estudar similares etc.

Síntese e Avaliação: nessas etapas é determinado mais um intervalo de tempo, de aproximadamente 15 a 20 minutos, para a conclusão deste processo. O propósito desse processo é detalhar e descrever a solução (ou soluções), de modo a confrontála com o "briefing", verificando sua aderência. (BAXTER, 2000)

\section{ESTUDO DE CASO}

Foi realizado um estudo de caso em uma empresa, que é líder mundial em serviços de teste, inspeção e certificação. Esta se faz presente em todas as áreas da economia apresentando soluções e serviços que contribuem para a potencialização dos negócios, uma vez que previne os riscos, oferecendo uma melhora na performance operacional e proteção à reputação e marcas dos clientes.

No contrato, onde o estudo de caso foi realizado, a empresa opera como prestadora de serviço, trabalha diariamente com emissão de notas fiscais de saídas de materiais. A situação problema resolvida através do brainstorming se encontra na distribuição 
do serviço de emissão de notas fiscais da empresa. O serviço era realizado através de e-mail no ano de 2019. Os Solicitantes (demais áreas da empresa) de NF-e enviavam um e-mail para um emissor dentre vários solicitando às notas fiscais necessárias para o transporte de seus materiais, ocorrendo assim um desnível enorme no volume de atendimento por emissor.

- Identificação do problema: desnível de produção, alguns funcionários se encontravam demasiadamente sobrecarregando outros ociosos.

- Organização da equipe: nosso Facilitador foi o gerente setorial e os membros do brainstorming foram os próprios funcionários da atividade em questão.

- Ambiente descontraído: os encontros foram realizados na sala de reunião da própria empresa.

Colocando em prática o brainstorming clássico.

- Orientação: momento de expor o problema, essa fase foi fácil pois os membros eram conhecedores e/ou reclamadores da situação problema.

- Preparação: exposição das ideias formuladas pelos integrantes da equipe. Nessa etapa foram levantadas várias ideias, todas anotadas em um quadro, contou com a participação de todos os envolvidos na tarefa.

- Análise: Posteriormente analisadas uma a uma, com a análise individual algumas foram eliminadas restando três ideias, essas foram a solução de curto, médio e longo prazo para o problema em questão.

- Ideação: conjunção de ideias propostas visando escolher uma ou mais alternativas a serem detalhadas. Primeira ideia de longo prazo, foi proposta a criação de um "robô" (sistema) que distribuísse o serviço do e-mail para todos emissores de forma uniforme. Segunda ideia de curto prazo, era que criasse um único e-mail recebedor do serviço e o mesmo tivesse um administrador que fizesse a distribuição do serviço. A terceira e última ideia/solução foi de que fosse desenvolvido um sistema onde todos visualizassem todo o serviço e assim pudessem seguir uma ordem de atendimento. Nesse estudo de caso a ordem de relevância utilizada nessa etapa foi de custo/tempo. 
- Incubação: Essa técnica não foi acionada em nosso estudo na primeira reunião, pois na etapa de ideação já se chegou a uma conclusão para a solução do problema. Durante a aplicação da ideia na prática, outros encontros de alinhamento aconteceram e novas ideias surgiram para a etapa de incubação.

- Síntese e Avaliação: Objetivo dessa fase é detalhar e descrever a solução (ou soluções) selecionada. O brainstorming realizado na empresa em sua avaliação final definiu como primeira medida a ser adotada a criação de um email recebedor do serviço e um administrador que fizesse a distribuição deste, esta foi a solução mais prática e de menor custo. Posteriormente, soluções com maiores custos e tempo foram levantadas, sendo necessário o desenvolvimento de um projeto com a integração da equipe de TI. Com auxílio da TI foi implantada a SST (solicitação de serviços técnicos) onde o solicitante não mais solicitava por e-mail, mas sim realizava os pedidos por esse portal não podendo ultrapassar a 5 pedidos por SST (denominação dada a cada pedido). Esta é recebida numa página visível a todos os emissores, no qual o serviço quando assumido por um emissor é visualizado pelos demais e atendidos por ordem de chegada, relembrando que esse novo sistema de atendimento nasceu da terceira ideia de nosso brainstorming. A primeira ideia, que ainda se encontra em estudo, é a de longo prazo.

Concluo que aplicação do brainstorming na situação problema da empresa, teve como foco alcançar soluções de baixo custo com pelo menos uma solução de imediato, esta foi alcançada numa dinâmica de grupo e de forma eficiente. Além disso, trouxe como ganho o envolvimento da equipe no processo, o que contribui com a satisfação e a motivação dos colaboradores.

\section{CONSIDERAÇÕES FINAIS}

A técnica de brainstorming tem sua notabilidade, pois possibilita que a atenção do usuário se volte ao fato gerador do problema, além de proporcionar uma ampla perspectiva de ideias, facilitando a tomada de melhores decisões, e ainda funcionar como lubrificante num processo de solução de problemas, facilitando a identificação de causas mais difíceis de solucionar, especialmente as não visíveis. 
Concluem-se que a inovação e criatividade andam juntas e ambos os processos são necessários num brainstorming. A inovação passou a ser fator determinante de desenvolvimento e sucesso. Para inovar faz-se necessário criatividade, uma produção criativa não pode ser simplesmente uma resposta nova, ela deve igualmente ser adaptada para satisfazer dificuldades ligadas às diferentes situações nas quais se encontram as pessoas.

O brainstorming Clássico, necessitando poucos recursos para seu desenvolvimento, ajuda a encontrar soluções de curto, médio e longo prazo atendendo às expectativas dos usuários. É um método que permite a participação de várias pessoas na tomada de decisões por meio da geração de ideias, sendo essa um fator relevante para solução de um problema ou melhoria do processo. Fazendo juízo a sua tradução, tempestade de ideias, O brainstorming, tem como propósito gerar o máximo de ideias possíveis sobre um determinado assunto dado a um período de tempo, buscando evitar decisões precipitadas.

A partir da análise de materiais já publicados e com o estudo de caso se chegou à conclusão que um brainstorming bem elaborado e ministrado pode lançar soluções inovadoras para a situação problema ou como pode também sugerir soluções simples que farão toda a diferença. Também foi observado no estudo de caso que a aplicação da técnica de brainstorming foi uma alternativa eficiente onde o envolvimento dos colaboradores na busca por soluções facilitou muito o desenvolvimento de todo o projeto e implantação, visto que os mesmos lidavam todos os dias com as emissões e puderam ajudar informado os erros que foram aparecendo no decorrer do processo. O brainstorming atingiu seu objetivo pois teve como foco alcançar soluções de baixo custo com pelo menos uma solução de imediato, tal solução foi alcançada numa dinâmica de grupo e de forma eficiente.

\section{REFERÊNCIAS}

\section{ALENCAR, E. M. L. S.; FLEITH, D. S. Contribuições teóricas recentes ao estudo} da criatividade. Psicologia: teoria e pesquisa, 2003. 
AMORIM, M. C. S.; FREDERICO, R. Criatividade, inovação e controle nas organizações. in: xxxii encontro da associação nacional de programas de pósgraduação em administração - enanpad, 32. anais... rio de janeiro: anpad, 2008.

ARAUJO, J. B.; ABREU JUNIOR, O. F.; ZILBER, S. N. Adoção de E-BUSINESS e geração de inovação. SIMPOI.2010. Disponível em: <http://www.simpoi.fgvsp.br/arquivo/2010/artigos/E2010_T00376_ PCN70113.pdf>. Acesso em: 20 abr. 2020.

BARBIERI, J. C.; ÁlVARES, A. C. T.; CAJAZEIRA, J. E. R. Gestão de Ideias para inovação contínua. Porto Alegre: Bookman, 2009.

BAXTER, M. - Projeto de Produto - Guia Prático para o Desenvolvimento de Novos Produtos - São Paulo, Editora Edgar Blücher, 1998.

BAXTER, M. - Projeto de Produto - Guia Prático para o Desenvolvimento de Novos Produtos - São Paulo, Editora Edgar Blücher, 2000.

CHIBÁS, F. O.; PANTALEÓN, E. M.; ROCHA, T. A. Gestão Da Inovação E Da Criatividade Na Atualidade. HOLOS, [S.I.], v. 3, p. 15-26, ago. 2013. ISSN 18071600.

COOPER, R. G.; EDGETT, S. J. Ideation for product innovation: what are the best methods. PDMA Visions, 2008.

DUGOSH, K. L.; PAULUS, P. B.; ROLAND, E. J.; YANG, H.C. Cognitive Stimulation in Brainstorming. Journal of Personality and Social Psychology, 2000.

HIDALGO, A.; ALBORS, J. Innovation management techniques and tools: a review from theory and practice. R\&D Management, 2008.

HOLT, Knut. The role of the user in product innovation. Technovafion, 1988.

KNELLER, G. F. Arte e ciência da criatividade. São Paulo: Ibrasa, 1978. 
KING, B.; SCHLICKSUPP, H. Criatividade: uma vantagem competitiva. Rio de Janeiro: Qualitymark Ed., 1999.

LUBART, T. Psicologia da Criatividade. Porto Alegre: Ed. Artmed, 2007.

MAXIMIANO, A. C. A. Administração de Projetos: como transformar ideias em resultados. 2. ed. - São Paulo: Atlas, 2002.

NIJSTAD, B. A.; DE DREU, C. K. W. Creativity and Group Innovation. International Association for Applied Psychology, 2002.

NUNES, P. Conceito de Gestão e de Gestor. 2006. Disponível em <<http://www.notapositiva.com/trab_professores/textos_apoio/gestao/01conc_gestao .htm>>. Acesso em 27 de março de 2020.

OSBOM, A., 1987. O Poder Criador da Mente: princípios e processos do pensamento criador e do "brainstorming". Traduzido por E. Jacy Monteiro. São Paulo: Ibrasa editora.

OSBORN, A. F. 1962. O poder criador da mente: princípios e processos do pensamento criativo. Ed. Ibrasa.

PAROLIN, S. R. H. A perspectiva dos líderes diante da gestão da criatividade em empresas da região metropolitana de Curitiba-PR. 2001. Dissertação (Mestrado em Administração) - UFRS, Porto Alegre.

PAULUS, P. B.; DZINDOLET, M. T. Social Influence Processes in Group Brainstorming. Journal of Personality and Social Psychology, 1993.

RIETZSCHEL, E. F.; NIJSTAD, B.; STROEBE, W. Productivity is not enough: a comparison of interactive and nominal brainstorming groups on idea generation and selection. Journal of Experimental Social Psicolog, 2006.

RITZMAN, Larry. Administração da Produção e Operações. São Paulo: Pearson Prentice Hall, Ed. 2004. 
SENS, M. J. A criatividade sob a ótica do processo comportamental. 1998. Dissertação (Mestrado em Engenharia da Produção) - Universidade Federal de Santa Catarina, Florianópolis.

SILVEIRA, A.; ROPELATO, M.; VIEIRA, S. S.; NASCIMENTO, S. Empreendedorismo: Produção Científica na base Scielo 2004-2008.

WECHSLER, S. M. Criatividade: descobrindo e encorajando. São Paulo: Ed. Psy, 1998.

WERTHEIMER, M. Productive thinking. New York: Harper \& Row, 1959.

Enviado: Agosto, 2020.

Aprovado: Outubro, 2020. 